\title{
Bitter taste perception in BaYaka hunter-gatherers
}

\section{Authors \& Affiliations}

1. Sarai Keestra, Department of Epidemiology and Data Science, Amsterdam UMC, University of Amsterdam, Amsterdam, the Netherlands; s.m.keestra@amsterdamumc.nl

2. Inez Derkx, Department of Anthropology, University of Zürich, Zürich, Switzerland; inezelisabeth.derkx@uzh.ch

3. Gaurav Sikka, NHS Greater London, London, United Kingdom;

4. Nikhil Chaudhary, Leverhulme Centre for Human Evolutionary Studies, Department of Archaeology, University of Cambridge, Cambridge, United Kingdom; nc542@cam.ac.uk

5. Gul Deniz Salali, Department of Anthropology, University College London, United Kingdom; guldeniz.salali@ucl.ac.uk

\section{Corresponding author}

Supplementary Information is available for this paper. Any correspondence and requests for materials should be addressed to Gul Deniz Salali, Department of Anthropology, University College London, United Kingdom; guldeniz.salali@ucl.ac.uk

\begin{abstract}
Aversion towards bitter tastes evolved across vertebrate species to enable the recognition of harmful plant toxins. Genetic background, mode of subsistence, and dietary factors may explain variation in bitter taste sensitivity between human ecologies. We are the first to examine bitter taste perception within a population at different levels of market-integration, conducting an experiment using phenylthiocarbamide (PTC) and thiourea (Thiourea) infused paper strips amongst the Mbendjele BaYaka hunter-gatherers from Congo. We investigated (i.) prevalence of bitter tasting phenotypes amongst the BaYaka; (ii.) differences between BaYaka who grew up in town and forest camps. We found that $45.1 \%$ of BaYaka experience PTC as bitter, and $42.5 \%$ experience Thiourea as bitter. There were no sex differences, however bitter tasting phenotypes were significantly more prevalent in town than in forest camps (PTC:64.1\%vs35.1\%; Thiourea:64.1\%vs31.1\%). Despite a shared genetic background, we found that BaYaka who grew up in town were more sensitive to bitter taste than those living in the forest, suggesting a developmental component in taste perception. We suggest that the dietary transition from wild to cultivated foods in BaYaka living in town and a decreased use of traditional plant medicine may underlie this variation in bitter taste perception.
\end{abstract}

Key words: traditional medicine; plant ecology; dietary transition; PTC; thiourea; BaYaka; bitter taste 


\section{Introduction}

Bitter taste perception evolved across vertebrate species to detect the presence of potentially toxic molecules in plants and evoke avoidance behaviour from such materials [1-3]. Aversion for bitter tastes is innate [4], but sensitivity decreases with age. Bitter taste perception is enabled by $\sim 25$ genes of the TAS2R family of Gprotein-coupled receptors that are expressed on the microvilli of taste bud cells on the tongue $[5,6]$. TAS2Rs help recognise a range of plant toxins such as goitrogenic thioamides, which upon ingestion interfere with the thyroid axis, can cause the enlargement of the thyroid gland, and increase thyroid cancer risk $[7,8]$. It is therefore evolutionarily advantageous to detect such bitter compounds to avoid their ingestion, and nearly all naturally occurring poisons are perceived by humans as bitter $[9,10]$. On the other hand, some naturally occurring bitter compounds such as caffeine in coffee, polyphenols in green tea, and flavonoid branched-chain glycosides in citrus fruits taste bitter but are not harmful to human health in small quantities [6,11-13]. Additionally, many medicinal compounds, such as willow-bark derived acetylsalicylic acid, the active compound in aspirin, activate the TAS2Rs bitter receptors, but are beneficial for health when consumed in small doses $[6,14]$.

In the 1930s it was discovered that variation existed in the perception of bitter taste in response to the synthetic compound phenylthiocarbamide (PTC) [15]. PTC binds to the same bitter taste receptor as the aforementioned thioamides, including compounds such as thiourea and goitrin [1]. PTC infused paper strips have since been used to test phenotypic ability to perceive bitter tasting compounds. Population variation in PTC sensitivity is found with $68.5 \%$ of white Americans of European descent perceiving PTC as bitter [16], compared to 93.9\% of Native Americans [17]. This has brought particular attention to the role of diet and subsistence strategy in understanding this variation [18]. Throughout the history of domestication of wild plants to cultivated crops it is generally thought that humans actively selected against toxic and distasteful plants, and as a result cultivated plants that are less bitter than their wild counterparts $[19,20]$. Dietary changes in the bitterness of foods consumed may have in turn affected the strength of selection of bitter taste loci in some agricultural populations, while a diet rich in plant toxins may select for increased bitter taste sensitivity [21]. Sjöstrand et al. (2020) looked at bitter taste perception among Baka hunter-gatherers and neighbouring Bantu farmers in Cameroon, comparing their ability to detect bark-derived bitter quinine, which is used as a malaria treatment and activates TAS2Rs [22,23]. Although one may have predicted that a population practicing hunting and gathering in a complex forest ecology would benefit from increased sensitivity to plant toxins, they found that Baka were less sensitive at detecting this bitter substance than the population practicing farming. However, whether subsistence strategy accounts for these differences remains debated. Campbell et al. 2017 investigated variation in bitter taste perception across populations in West, Central, and East Africa with diverse subsistence 
strategies, ranging from hunting-gathering and pastoralism to agriculture [24]. Although there was a large variation in bitter taste perception across these populations, TAS2R38 haplotype variation, which accounts for 55-85\% of the phenotypic variation in responses to bitter compounds [25], was not correlated to geography or diet [24].

One explanation for the contradictory results regarding the association between bitter taste variation with geography or diet may be because bitter taste perception is a more plastic trait than originally assumed. No study thus far has investigated variation of bitter taste perception with regards to lifestyle transitions within a single population. The possibility that dietary differences during development within the same population affect bitter tasting phenotypes remains to be explored. To address this gap, we examined whether a population of forest hunter-gatherers exhibit variation in bitter taste perception according to levels of market integration and cultivated foods in their diet. We conducted a bitter taste perception experiment amongst the Mbendjele hunter-gatherers, who are a subgroup of BaYaka huntergatherers living in the rainforests of the Republic of Congo. Consumption of wild plants for medicinal use is traditionally very important amongst the BaYaka [26,27], who are known for their rich knowledge and diverse exploitation of wild plants [27]. The BaYaka often use bitter tree barks for treatment purposes, boiling them and consuming the juice for digestive disorders (caused by parasitic infections), one of the most common illnesses among forest hunter-gatherers [26]. The BaYaka exhibit variation in market integration and subsistence strategies - some are born and raised in large settlements near farmer villages and market towns and engage in crop cultivation and wage labour, while others grow up in smaller camps in the forest, relying more heavily on hunting and gathering [28]. Not only do the BaYaka differ in access to cultivated foods, those who grew up in town report knowing and using fewer wild plants and preferring western medicine over traditional plant medicine [29]. Considering the frequent consumption of such bitter substances for medicinal purposes and the previous findings by Sjöstrand et al. 2020 in a related huntergatherer population [22,27,29], we hypothesised that the BaYaka may be less sensitive to bitter taste if they more frequently consume wild plants and more regularly make use of traditional plant medicine. By conducting a bitter taste experiment in town-born versus forest-born BaYaka hunter-gatherers, we tested if exposure to bitter substances during development affects variation in bitter taste perception. 


\section{Methods}

\section{Field work and study population}

We conducted fieldwork in three different BaYaka campsites in northern Republic of Congo in July and August 2018. One campsite was located near a logging town, Pokola, and consisted of individuals who are born and raised there, and families who temporarily move there to visit relatives or buy products in the market. Here we exclusively recruited individuals that were born and grew up in Pokola. The BaYaka who are born and raised in town engage in wage labour more frequently [28], know fewer wild plants [27], and prefer western medicine over traditional treatment practices [29] compared to their forest dwelling counterparts. We also recruited individuals from two forest campsites (Longa and Njoki), which were located in forest near a dirt road. The BaYaka living in forest camps primarily engage in hunting and gathering, but also trade some forest items with Bantu farmers in return for cigarettes, alcohol and cultivated foods. However, BaYaka living in the town can more easily access cultivated foods through Bantu shops and the local market in Pokola.

\section{Taste perception experiment}

We used paper strips containing either phenylthiocarbamide (PTC) or thiourea compounds, in a concentration of approximately $\sim 30 \mathrm{mcg} / \mathrm{strip}$, and plain papers (as a control) by Eisco Laboratories. Participants were given a control paper first, then PTC and finally Thiourea. Participants were asked to describe the taste of the papers in an open-ended question. Only individuals that experienced the control paper as tasteless, sweet, or salty were included in the analyses, whereas those who described the control as bitter were excluded. Interviews were conducted in Mbendjele (the language spoken by the study population) with the help of a Mbendjele translator who translated from French to Mbendjele.

\section{Study sample}

Of the 143 participants, 30 did not pass the control test (Supplementary File 1). All other participants, 58 women and 55 men, living in the forest camps $(n=74)$ or the town camp $(n=39)$ were included in the study.

\section{Data analysis}

Mean percentages of tasters of PTC and thiourea were calculated, where "tasting" was defined as individuals that described experiencing the PTC or thiourea paper using terms such as 'bitter', 'a bit bitter', or 'very bitter' in their answer. "Non-tasting" was defined as people describing the taste as nothing, sweet, or salty. We performed logistic regression analyses to examine the effect of camp residence and sex on the 
odds of PTC and thiourea bitter tasting (tasters coded as 1, and non-tasters as 0 ). Analyses were conducted in R Studio version 1.3.959.

\section{Results}

Less than $50 \%$ of the BaYaka has a bitter tasting phenotype

Of the 113 individuals included, 45.1\% (51/113) experienced the PTC paper as bitter, $50.4 \%$ (57/113) were non-tasters of PTC, describing the PTC paper as being tasteless, sweet, or salty, and a small proportion $(4.4 \% ; 5 / 113)$ described it as hot (Supplementary 1). Additionally, 42.5\% ( $n=48 / 113)$ experienced the Thiourea paper as bitter, 55.7\% (63/113) as nothing, sweet, or salty, and 1.8\% (2/113) as hot.

Bitter tasting phenotype is more frequent amongst town-born hunter-gatherers Because there was no significant difference between the proportion of tasters in the two forest camps, we combined their responses (PTC: Longa: $n=16 / 49$ and Njoki:10/25; thiourea Longa $15 / 49$ and Njoki = 8/25). The percentage of bitter tasters for both the PTC and thiourea was higher in town-born BaYaka than the participants from the forest camps (Figure 1). Our regression models showed that town-born BaYaka were three times more likely to taste PTC and thiourea as bitter than BaYaka living in the forest (Table 1).

No sex difference in bitter taste perception amongst the BaYaka

There were no significant difference in PTC and thiourea tasting according to sex (Figure 2, Table 1). 


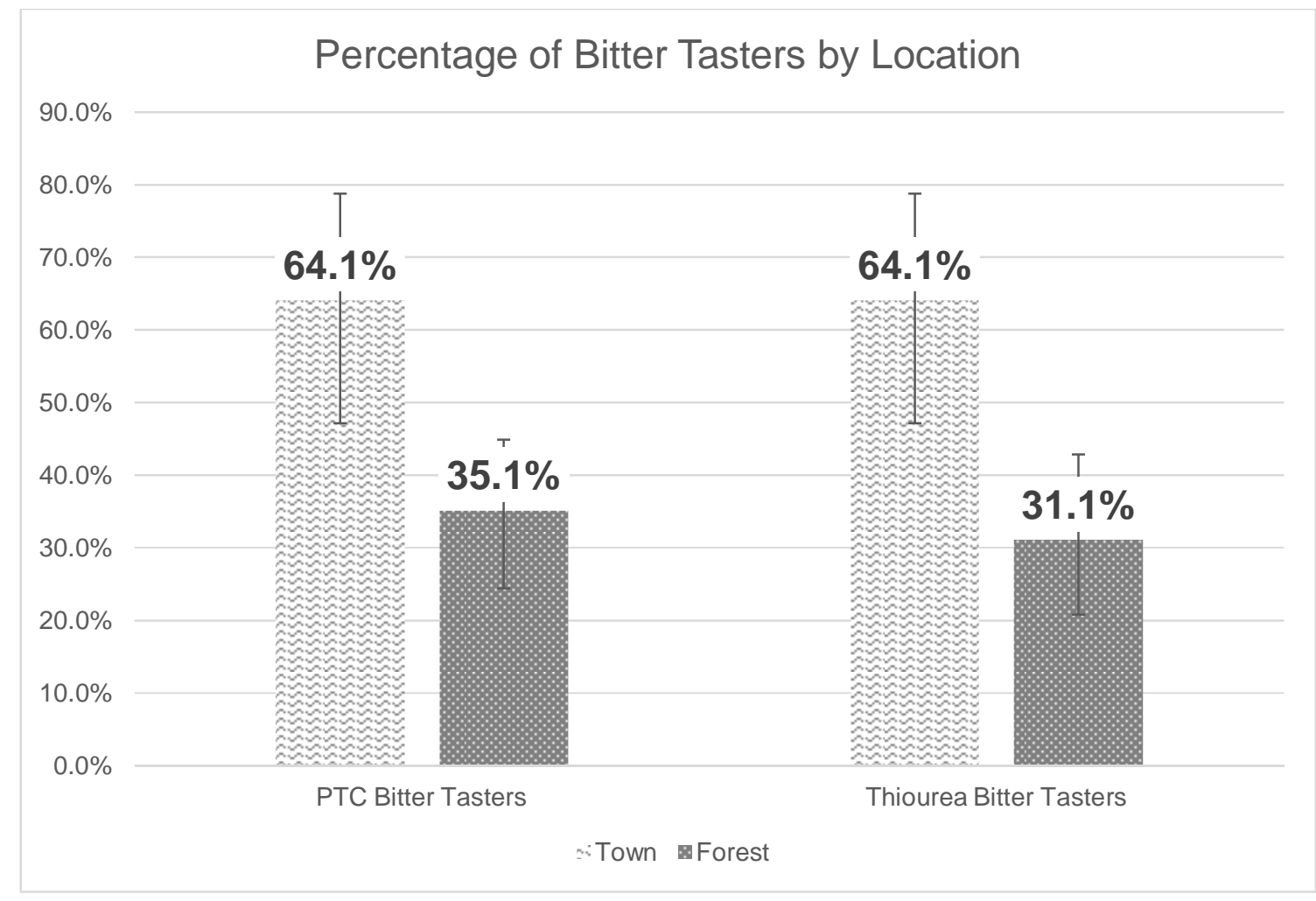

Figure 1: Percentage of PTC and thiourea bitter tasters per location (BaYaka in town $n=39$, BaYaka in forest camps $n=74$ ).

\begin{tabular}{|l|l|l|l|}
\hline \multicolumn{2}{|c|}{ Odds ratio } & $\begin{array}{l}\text { 95\% Confidence } \\
\text { Interval }\end{array}$ & P-value \\
\hline \multicolumn{3}{|c|}{ PTC } & \\
\hline Town vs forest & 3.04 & $1.35-7.09$ & 0.008 \\
\hline Men vs women & 0.56 & $0.25-1.23$ & 0.151 \\
\hline \multicolumn{3}{|c|}{ Thiourea } \\
\hline Town vs forest & 3.85 & $1.71-9.00$ & 0.001 \\
\hline Men vs women & 0.68 & $0.30-1.50$ & 0.342 \\
\hline
\end{tabular}

Table 1: Logistic regression modes for PTC and Thiourea bitter tasting per camp location and sex. Significant differences are highlighted in bold. 


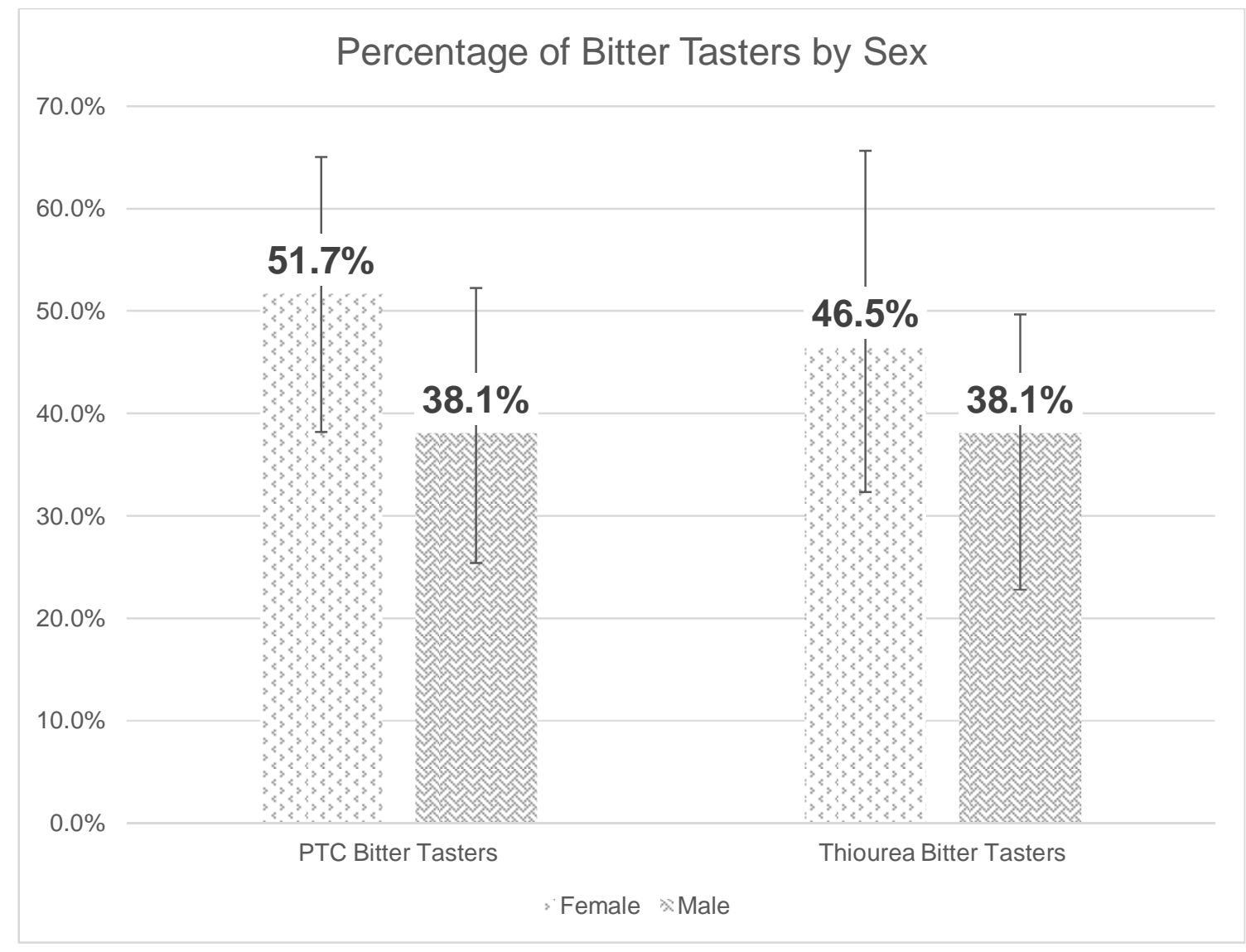

Figure 2: Percentage of PTC and thiourea tasters per sex. For the taste perception experiment, 58 women and 55 men participated after passing the control strip. 30 women and 21 men perceived the PTC paper strip as bitter. For Thiourea, bitter taste was perceived by 27 women and 21 men.

\section{Discussion}

In this study of bitter taste perception among BaYaka hunter-gatherers at different levels of market integration we found the bitter tasting phenotype to be more prevalent amongst individuals born and raised in town than those who were living in the forest. The PTC bitter tasting phenotype prevalence of $64.1 \%$ in town is more similar to the prevalence of the bitter tasting phenotype found in Westernised populations of European ancestry ( 60-70\%) [16,29], whereas in forest camps $35.1 \%$ were PTC bitter tasters which is much lower than found amongst Western industrialised populations. For thiourea the tasting prevalence was even lower, as only $31.1 \%$ of BaYaka who grew up in the forest camps reported this goitrogenic substance as tasting bitter. Our findings suggest that sensitivity to bitterness may vary in adulthood according to the chemical ecology encountered during development rather than being determined by underlying genetics alone. Here we showed that within the Mbendjele BaYaka, lifestyle and diet influence bitter taste perception despite a shared genetic background. 
Both tasting and non-tasting phenotypes might have evolutionary advantages $[31,32]$. For example, non-tasters may be less fussy and more open to exploring a variety of different plant-based foods $[21,32]$, or better able to ingest a wider range of plant compounds [31,32]. Click or tap here to enter text.Click or tap here to enter text.A possible explanation for differences in bitter taste perception between forest and town-born BaYaka could be that although the BaYaka in the forest may consume a diet that is higher in various plant toxins, it is possible to learn to tolerate particular types of plant toxins if one is exposed to them during early life and if they confer benefits when consumed in small quantities. In non-human primates, for instance, decreased sensitivity to bitter tastes has evolved as an adaptation to leaf-eating behaviour [1,34]. The BaYaka use and consume plants, especially bitter barks, mostly for medicinal purposes [26,27]. In communities where plant treatments are commonly used as medicine, from the ancient Greeks to the agro-pastoralist Arbëresh peoples, the potency of medicinal plants is often derived from the bitterness of their taste $[18,35]$. Indeed, when asked, the Arbëresh distinguish between plants meant for consumption and those meant for medicinal use by classifying them by their degree of bitterness [35]. Compared to those born in town, BaYaka living in the forest use more wild plants for medicine and prefer traditional treatment methods which often involves boiling of barks and consuming the bitter juice [26,27,29]. It has been previously documented that there is an overlap between the plant species used by the BaYaka and Baka and plants used by gorillas and chimpanzees inhabiting the same region for the purpose of self-medication [27]. Previous research has furthermore highlighted a connection between the ingestion of bitter plants among chimpanzees and their anti-parasitic effects $[21,36]$. Most medicinal plants used by the BaYaka have documented bioactive properties and the majority of the medicinal uses concern treating digestive and respiratory disorders and infections [27]. Therefore, in the high-pathogen ecology of the BaYaka living in the forest, it may be advantageous to be less aversive to the bitter taste of plants and barks containing medicinal properties that may confer a survival advantage when consumed at low doses. This aligns with the findings of Sjöstrand et al. (2020) who found the Baka in Cameroon to be less sensitive to bark-derived quinine than neighbouring farming groups [22]. Based on the findings of the taste experiment presented here, we hypothesise that as a result of the chemical ecology that BaYaka encounter as children, the tolerance and therefore detection threshold for bitter tastes amongst those who grew up in the forest may be higher.

Another possible explanation for variation in bitter taste perception between those more regularly consuming wild plants versus agricultural products may be differences in the consumption of the cultivated staple food cassava $[21,26]$, which is rich in the goitrogen thiocyanate [37,38], and more easily accessible to BaYaka living in the town. Particularly, the PTC compound contains the $\mathrm{N}-\mathrm{C}=\mathrm{S}$ moiety found in the thiocyanate toxin in cassava, cabbage, and other plants of the Brassica family [39], which gives these cultivated crops a distinctive bitter taste. Bitter tasting phenotype, 
especially of PTC, correlates with the ability to perceive naturally occurring goitrogens such as thiocyanate [40], potentially leaving non-tasters at risk of certain types of thyroid disease. Amongst Ecuadorian Andeans, who consume a diet naturally high in goitrogens in an iodine deficient region, PTC sensitivity was found to be high $(93.5 \%)[18,41]$. It may be possible that differences in the frequency of cassava consumption in early life, and consequent exposure to thiocyanate, may have rendered town-born BaYaka to be more sensitive to bitter tastes.

Our taste experiment suffered from several limitations. Firstly, our sample size was small as the BaYaka mostly live in groups fewer than 60 individuals [42]. Secondly, we only used a single concentration of PTC and Thiourea, which precluded an assessment whether there are differences in bitter taste threshold between the forest and town BaYaka groups. Finally, further anthropological studies on the terminology of different tastes and gradations of "bitter" in the BaYaka are needed to better understand the gradient of perception of bitter compounds in this population and how it is correlated with food and treatment choices.

\section{Conclusion}

In a hunter-gatherer population, we found that individuals living in forest are less sensitive to bitter taste than those who grew up in a town with higher access to cultivated food items and reduced use of medicinal plants. Our findings challenge the commonly held assumption that bitter taste perception is genetically determined and suggests the existence of a developmental component in bitter tasting phenotype.

\section{Acknowledgements}

We would like to express our thanks to all Mbendjele BaYaka who participated in our study. We are grateful for their participation and hospitality during the project. Our particular thanks go to our translators Nicolas, Roger, and Mindoula for their invaluable help in data collection. We also would like to thank Jerome Lewis, Clobite Bouka Biona, and Laure Stella Ghoma Linguissi for their help with fieldwork logistics and research permits.

\section{Author contributions}

G.D.S conceived the project; S.K, G.D.S., N.C., G.S., I.D., collected the data; S.K. conducted the analyses and wrote the manuscript under supervision of G.D.S.; all authors reviewed and approved the final manuscript. 


\section{Financial support}

This project was funded by the British Academy Post-doctoral Research Fellowship and research grant SRGl171409 to G.D.S.

\section{Conflicts of interest}

The authors declare no competing interests.

\section{Ethics}

The research and fieldworks were approved by the Ethics Committee of University College London (ethics code: 13121/001) and the methods were carried out in accordance with the approved guidelines. Informed consent was obtained from all participants and research permission granted by the Republic of Congo's Ministry of Scientific Research.

\section{Bibliography}

1. Purba LHPS, Widayati KA, Suzuki-Hashido N, Itoigawa A, Hayakawa T, Nila S, Juliandi B, Suryobroto B, Imai H. 2020 Evolution of the bitter taste receptor TAS2R38 in colobines. Primates 61, 485-494. (doi:10.1007/s10329-02000799-1)

2. Behrens M, Meyerhof W. 2006 Bitter taste receptors and human bitter taste perception. Cellular and Molecular Life Sciences 63, 1501-1509. (doi:10.1007/s00018-006-6113-8)

3. Breslin PAS. 2013 An Evolutionary Perspective on Food and Human Taste. Current Biology 23, R409-R418. (doi:10.1016/j.cub.2013.04.010)

4. Steiner JE. 1977 Facial expressions of the neonate infant indicating the hedonics of food-related chemical stimuli. In Taste and Development: The Genesis of Sweet Preference (ed JM Weiffenbach), pp. 173-188. Washington, DC: U.S. Government Printing Office.

5. Roudnitzky N, Risso D, Drayna D, Behrens M, Meyerhof W, Wooding SP. 2016 Copy number variation in TAS2R bitter taste receptor genes: Structure, origin, and population genetics. Chemical Senses 41, 649-659.

(doi:10.1093/chemse/bjw067)

6. Meyerhof W, Batram C, Kuhn C, Brockhoff A, Chudoba E, Bufe B, Appendino G, Behrens M. 2009 The molecular receptive ranges of human TAS2R bitter taste receptors. Chemical Senses 35, 157-170. (doi:10.1093/chemse/bjp092)

7. Mixner JP, Reineke EP, Turner CW. 1944 Effect of Thiouracil and Thiourea on the Thyroid Gland of the Chick. Endocrinology 34, 168-174.

(doi:10.1210/endo-34-3-168)

8. Purves HD, Griesbach WE. 1947 Studies on experimental goitre; thyroid tumours in rats treated with thiourea. British journal of experimental pathology 28, 46-53.

9. Bate-Smith EC. 1972 Attractants and repellents in higher animals. In Phytochemical ecology: Proceedings of the phytochemical society symposium. (ed JB Harborne), pp. 45-56. London: Academic Press.

10. Glendinning Jl. 1994 Is the bitter rejection response always adaptive? Physiology and Behavior 56, 1217-1227. (doi:10.1016/0031-9384(94)90369-7) 
11. Nissim I, Dagan-Wiener A, Niv MY. 2017 The taste of toxicity: A quantitative analysis of bitter and toxic molecules. IUBMB Life 69, 938-946.

(doi:10.1002/iub.1694)

12. Tarragon E, Moreno JJ. 2020 Polyphenols and taste 2 receptors. Physiological, pathophysiological and pharmacological implications. Biochemical

Pharmacology. 178, 114086. (doi:10.1016/j.bcp.2020.114086)

13. Frydman A, Liberman R, Huhman D V, Carmeli-Weissberg M, Sapir-Mir M, Ophir R, Sumner LW, Eyal Y. 2012 The molecular and enzymatic basis of bitter/non-bitter flavor of citrus fruit: evolution of branch-forming rhamnosyltransferases under domestication. (doi:10.1111/tpj.12030)

14. Reinberger S. 2006 Bitter could be better. Scientific American 17.

15. Fox AL. 1932 The Relationship Between Chemical Constitution and Taste. Proc. N.A.S. 18.

16. Snyder LH. 1931 Inherited Taste Deficiency. Science 74, 151-152.

17. Levine P, Anderson AS. 1932 Observations on taste blindness. Science 75, 497-498. (doi:10.1126/science.75.1949.497)

18. Johns T. 1990 With Bitter Herbs They Shall Eat It: Chemical Ecology and the Origins of Human Diet and Medicine. Arizona Studies in Human Ecology.

19. Whitehead SR, Turcotte MM, Poveda K. 2017 Domestication impacts on plantherbivore interactions: a meta-analysis. Philosophical Transactions of the Royal Society B 372. (doi:10.1098/rstb.2016.0034)

20. Che G, Zhang X. 2019 Molecular basis of cucumber fruit domestication. Current Opinion in Plant Biology. 47, 38-46. (doi:10.1016/j.pbi.2018.08.006)

21. Wooding SP, Ramirez VA, Behrens M. 2021 Bitter taste receptors: genes, evolution, and health. Evolution, Medicine, and Public Health (doi:10.1093/EMPH/EOAB031)

22. Sjöstrand AE, Sjödin P, Hegay T, Nikolaeva A, Shayimkulov F, Blum MGB, Heyer E, Jakobsson M. 2020 Taste perception and lifestyle: insights from phenotype and genome data among Africans and Asians. European Journal of Human Genetics (doi:10.1038/s41431-020-00736-2)

23. Gachelin G, Garner P, Ferroni E, Tröhler U, Chalmers I. 2017 Evaluating Cinchona bark and quinine for treating and preventing malaria. Journal of the Royal Society of Medicine 110, 31-40. (doi:10.1177/0141076816681421)

24. Campbell MC et al. 2012 Evolution of Functionally Diverse Alleles Associated with PTC Bitter Taste Sensitivity in Africa. Molecular Biology and Evolution 29, 1141-1153. (doi:10.1093/molbev/msr293)

25. Kim U kyung, Jorgenson E, Coon H, Leppert M, Risch N, Drayna D. 2003 Positional cloning of the human quantitative trait locus underlying taste sensitivity to phenylthiocarbamide. Science 299, 1221-1225.

(doi:10.1126/science.1080190)

26. Salali G. 2017 Social structure and knowledge sharing networks in huntergatherers: A case study on the plant knowledge of the Mbendjele BaYaka Pygmies. Doctoral thesis, UCL (University College London).

27. Salali GD et al. 2016 Knowledge-Sharing Networks in Hunter-Gatherers and the Evolution of Cumulative Culture. Current Biology 26, 2516-2521. (doi:10.1016/j.cub.2016.07.015)

28. Salali GD, Migliano AB. 2015 Future discounting in congo basin huntergatherers declines with socio-economic transitions. PLOS ONE 10, 1-10. (doi:10.1371/journal.pone.0137806) 
29. Salali GD et al. 2020 Global WEIRDing: Transitions in Wild Plant Knowledge and Treatment Preferences in Congo Hunter-Gatherers. Evolutionary Human Sciences 2. (doi:10.1017/ehs.2020.26)

30. Parr LW. 1934 Taste Blindness and Race. The Journal of Heredity 25, 187190.

31. Wooding S. 2006 Phenylthiocarbamide: A 75-Year Adventure in Genetics and Natural Selection. Genetics. 172. (doi:10.1093/GENETICS/172.4.2015)

32. Bamshad MJ, Motulsky AG. 2008 Health consequences of ecogenetic variation. In Evolution in Health and Disease (eds SC Stearns, JC Koella), Oxford University Press.

33. Ullrich N V., Touger-Decker R, O'sullivan-Maillet J, Tepper BJ. 2004 PROP taster status and self-perceived food adventurousness influence food preferences. Journal of the American Dietetic Association 104, 543-549. (doi:10.1016/j.jada.2004.01.011)

34. Purba LHPS, Widayati KA, Tsutsui K, Suzuki-Hashido N, Hayakawa T, Nila S, Suryobroto B, Imai H. 2017 Functional characterization of the TAS2R38 bitter taste receptor for phenylthiocarbamide in colobine monkeys. Biology Letters 13. (doi:10.1098/rsbl.2016.0834)

35. Pieroni A, Nebel S, Quave C, Münz H, Heinrich M. 2002 Ethnopharmacology of liakra: Traditional weedy vegetables of the Arbëreshë of the Vulture area in southern Italy. Journal of Ethnopharmacology 81, 165-185. (doi:10.1016/S0378-8741(02)00052-1)

36. Koshimizu K, Ohigashi H, Huffman MA. 1994 Use of Vernonia amygdalina by wild chimpanzee: Possible roles of its bitter and related constituents. Physiology \& Behavior 56, 1209-1216. (doi:10.1016/0031-9384(94)90368-9)

37. Chen ZP, Hetzel BS. 2010 Cretinism revisited. Best Practice and Research: Clinical Endocrinology and Metabolism 24, 39-50. (doi:10.1016/j.beem.2009.08.014)

38. Ermans AM, Mbulamoko NM, Delange F, Ahluwalia R. 1980 Role of Cassava in the Ethiology of Endemic Goitre and Cretinism. Ottawa, Canada: International Development Research Centre.

39. Bufe B, Breslin PAS, Kuhn C, Reed DR, Tharp CD, Slack JP, Kim U-K, Drayna D, Meyerhof W. 2005 The Molecular Basis of Individual Differences in Phenylthiocarbamide and Propylthiouracil Bitterness Perception. Current Biology 15, 322-327.

40. Boyd WC. 1950 Taste reactions to antithyroid substances. Science 112, 153. (doi:10.1126/science.112.2901.153)

41. Greene LS. 1974 Physical growth and development, neurological maturation, and behavioral functioning in two Ecuadorian Andean communities in which goiter is endemic. II. PTC Taste sensitivity and neurological maturation. American Journal of Physical Anthropology 41, 139-151. (doi:10.1002/ajpa.1330410118)

42. Dyble M, Salali GD, Chaudhary N, Page A, Smith D, Thompson J, Vinicius L, Mace R, Migliano AB. 2015 Sex equality can explain the unique social structure of hunter - gatherer bands. Science (doi:10.1126/science.aaa5139) 